\title{
A pilot study of individualized maximum repeatable dose (iMRD), a new dose finding system, of weekly gemcitabine for patients with metastatic pancreas cancer
}

\author{
Y. Takahashi and K. Yamashita
}

We developed and established a new dose-finding system, the individualized maximum repeatable dose (iMRD), suitable to induce prolonged TTP rather than tumor shrinkage.

We applied this system in weekly gemcitabine therapy for 18 metastatic pancreas cancer patients. We determined the iMRD at the 5 th week, after weekly dose adjustments. We started at $500 \mathrm{mg} / \mathrm{m}^{2}$ (1/2 MTD (maximum tolerated dose)) of gemcitabine and repeated the treatment with an increase or a decrease of $100 \mathrm{mg} / \mathrm{m}^{2}$ each week, if toxicity was 0 or more than grade 1, respectively (Figure 1).

The iMRD of weekly gemcitabine was $300 \mathrm{mg} / \mathrm{m}^{2}$ in 2 patients, $400 \mathrm{mg} / \mathrm{m}^{2}$ in 3 patients, 500 $\mathrm{mg} / \mathrm{m}^{2}$ in 5 patients, $600 \mathrm{mg} / \mathrm{m}^{2}$ in 6 patients, and $700 \mathrm{mg} / \mathrm{m}^{2}$ in 2 patients, demonstrating significant differences among individual patients. Grade 3 marrow depression occurred in only 1 patient (5.6\%). Of these 18 patients, $3(16.7 \%), 13(72.2 \%)$ and $2(11.1 \%)$ patients showed PR, SD and PD, respectively. The median of TTP and survival was 4.5 months and 9.5 months, respectively. There were no significant differences in 1 year survival time and more than $50 \%$ reduction rate of serum CA19-9, a tumor marker for pancreatic cancer, between patients with lower $\left(500 \mathrm{mg} / \mathrm{m}^{2}\right.$ or less) and higher $\left(600 \mathrm{mg} / \mathrm{m}^{2}\right.$ or more) iMRD.

These results suggest that iMRD is a simple method to determine an individual's tailored dose for chemotherapy and could be the optimal dose for patients with non-curable cancers such as metastatic pancreas cancer.

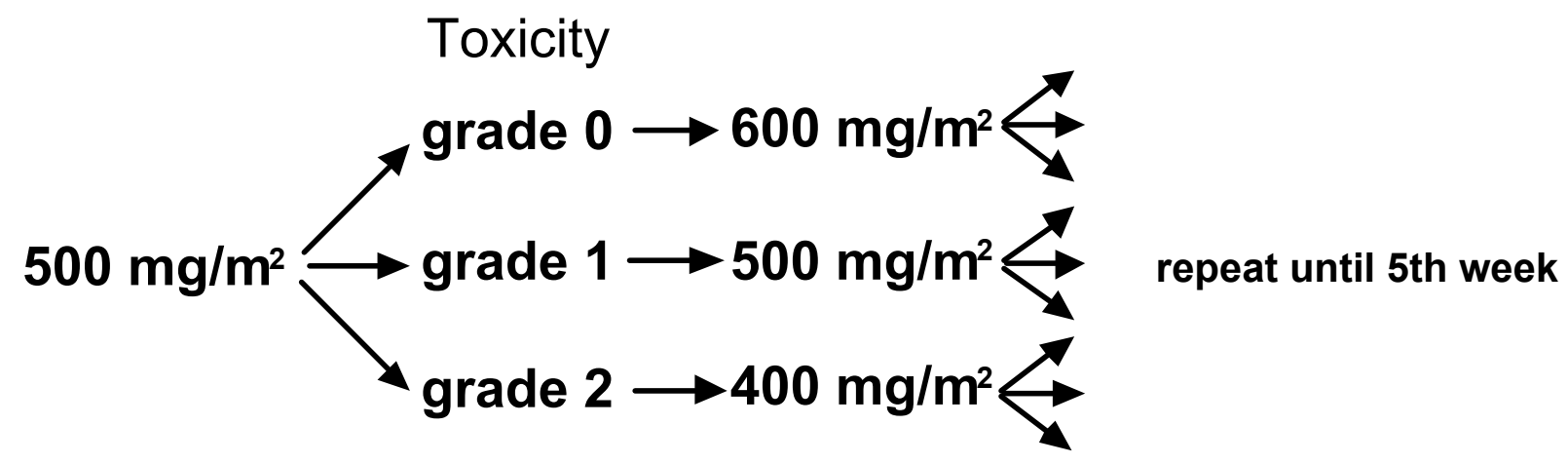

Figure 1. The method of determination of iMRD 